\title{
08
}

\section{Participación ciudadana en la defensa del territorio del Aljarafe sevillano}

\author{
Mario Caña Varona \\ Asociación en Defensa del \\ Territorio del Aljarafe (ADTA)
}

La Asociación en Defensa del Territorio del Aljarafe (ADTA) es una organización sin ánimo de lucro que promueve la habitabilidad y sostenibilidad en la comarca del Aljarafe y, en general, en el conjunto del área metropolitana de Sevilla. El Aljarafe, dada su cercanía a la capital andaluza, ha experimentado un fuerte desarrollo en las últimas décadas, que en muchas ocasiones ha ido en detrimento del medioambiente y la calidad de vida de sus ciudadanos. En este contexto surge ADTA con la intención de preservar los importantes valores culturales y naturales que esta comarca histórica aún mantiene. Entre las actividades que esta asociación lleva a cabo está la participación en la toma de decisiones a través de alegaciones a planes y proyectos, organización de debates o visitas guiadas sobre temas controvertidos; actividades de sensibilización y difusión o cooperación y asesoramiento; y acciones legales, entre otras. ADTA también elabora propuestas como "Riopudio, corredor verde del Aljarafe" con el fin de restaurar y proteger este arroyo y su entorno; o la propuesta "Parque Arqueológico y Paisajístico del Aljarafe Norte", que persigue proteger y poner en valor el rico patrimonio del norte de la comarca que aglutina el yacimiento calcolítico de Valencina y Castilleja de Guzmán, el yacimiento del Carambolo y la ciudad romana de Itálica.

En sus casi 20 años de historia ADTA ha podido presenciar la aparición, la explosión y el resurgimiento en nuestros días de la burbuja inmobiliaria. Hemos sido testigos de cómo la presión y especulación urbanística ha ocupado extensos territorios afectando al patrimonio natural y cultural e incluso dejándonos desoladores paisajes como el de las urbanizaciones "fantasma" tras la crisis económica. También hemos presenciado con satisfacción cómo algunas de nuestras acciones han surtido efecto, e incluso cómo algunas de nuestras propuestas se han materializado. Este es el caso del parque del Riopudio, que luce restaurado y acondicionado para su disfrute por parte de la ciudadanía del Aljarafe, no sin la amenaza de un deterioro próximo a causa de la ausencia de un marco de gestión adecuado. Un futuro incierto se cierne asimismo sobre el patrimonio histórico del Aljarafe norte donde la presión urbanística, la falta de sensibilidad y la incapacidad de poner en pie una estrategia conjunta de administración y gestión constituyen todavía una amenaza.
"Las mayores dificultades a las que se enfrenta la asociación son la inacción, mala gestión y falta de transparencia de las administraciones y autoridades públicas" 
Desde su creación en 1999, ADTA ha evolucionado gracias a la labor voluntaria que desempeñan los ciudadanos que la integran. Esta asociación, a pesar de su reducido tamaño, desarrolla gran cantidad de actividades para defender el territorio en sí mismo, entendido como el conjunto de valores naturales y culturales heredados y que debemos legar a las generaciones futuras. Hemos querido realizar una reflexión en conjunto sobre la implicación de la ciudadanía en el ámbito de este patrimonio, realizando una encuesta online de siete preguntas a nuestros socios y simpatizantes. El análisis de las respuestas de los 31 participantes de la encuesta nos permite reflexionar desde la perspectiva de la sociedad civil y particularmente en el contexto de esta asociación.

Sobre la evolución de la implicación de la ciudadanía en la defensa del territorio en los últimos 25 años, la mayoría de los encuestados está de acuerdo en que esta evolución ha sido positiva, aunque de ellos la mitad se inclina a pensar que esta evolución ha sido lenta o escasa, mientras que la otra mitad opina que ha sido progresiva o suficiente. Por otro lado, varios encuestados opinan que apenas ha habido evolución, pero ninguno afirma que esta evolución ha sido negativa. Existe un gran consenso sobre la existencia de una mayor concienciación y sensibilización en la sociedad en general, aunque el compromiso e implicación de los ciudadanos sea aún débil.

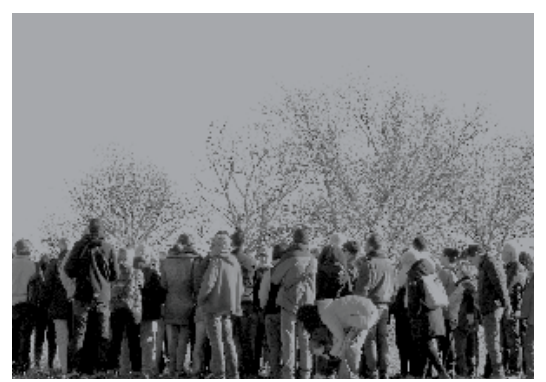

Visita a los acueductos del Aljarafe. Foto José Luis Bueno Mingallón

\section{"Un futuro incierto se cierne asimismo sobre el patrimonio histórico del Aljarafe norte donde la presión urbanística, la falta de sensibilidad y la incapacidad de poner en pie una estrategia conjunta de administración y gestión constituyen todavía una amenaza"}

Los motivos que mueven a los ciudadanos a involucrarse en ADTA son diversos,

destacando valores como su independencia, compromiso y espíritu crítico. La lucha contra la presión urbanística, la defensa del territorio, su sostenibilidad y los valores culturales y medioambientales son muy apreciados entre los encuestados. La principal dificultad para participar se debe a falta de tiempo, aunque ocasionalmente también a la falta de conocimientos. Las mayores dificultades a las que se enfrenta la asociación son la inacción, mala gestión y falta de transparencia de las administraciones y autoridades públicas. En un segundo lugar están la corrupción, especulación e intereses económicos y políticos cortoplacistas, junto a la insensibilidad y falta de compromiso de la ciudadanía.

Los retos de futuro en la defensa del territorio están relacionados principalmente con la capacidad de concienciación e implicación social. También con la capacidad de influir en la toma de decisiones de las administraciones para que estas velen por lo público. Estar presente en los medios de comunicación y redes sociales, una mayor participación de la ciudadanía, unido a la colaboración con otros colectivos son medidas que mejorarían la labor de ADTA en la defensa del territorio del Aljarafe, comarca que, con más de 350.000 habitantes hoy día, constituye por sí misma una de las grandes aglomeraciones urbanas de Andalucía. 